\title{
Experimental inoculation of adult dairy cows with bovine coronavirus and detection of coronavirus in feces by RT-PCR
}

\author{
Brief Report \\ H. Tsunemitsu ${ }^{1,2}$, D. R. Smith ${ }^{1, *}$, and L. J. Saif ${ }^{1}$ \\ ${ }^{1}$ Food Animal Health Research Program, Ohio Agricultural Research and Development \\ Center, The Ohio State University, Wooster, Ohio, U.S.A. \\ ${ }^{2}$ Hokkaido Research Station, National Institute of Animal Health, \\ Sapporo, Hokkaido, Japan
}

Accepted August 5, 1998

Summary. A reverse transcriptase PCR (RT-PCR) targeting a 407 bp fragment of the nucleocapsid gene of bovine coronavirus (BCV) was developed for detection of BCV RNA in feces of experimentally inoculated cattle. The sensitivity and specificity of the RT-PCR were confirmed using tissue culture-adapted BCV strains and feces of 2 calves inoculated with BCV. Ten nonpregant, BCV seropositive, adult dairy cows were inoculated with winter dysentery (WD) $(n=8)$ or calf diarrhea $(\mathrm{CD})(\mathrm{n}=2)$ strains of BCV intranasally and orally $(\mathrm{n}=2)$ or through a surgically-placed duodenal catheter $(\mathrm{n}=8)$ with and without dexamethasone treatment or feeding ice water. The 6 cows inoculated with BCV intranasally and through a duodenal catheter ( 2 of 2 cows given $\mathrm{CD}$ BCV and 4 of 6 cows given WD BCV) developed mild diarrhea, and BCV was detected in diarrheal feces by RT-PCR, ELISA or immune electron microscopy. These results suggest that CD and WD strains of $\mathrm{BCV}$ can cause diarrhea in adult cows in conjunction with host or environmental factors and that RT-PCR might be useful to diagnose BCV infections in calves and adult cows.

$*$

Bovine coronavirus (BCV) is an important pathogen of neonatal calf diarrhea (CD) [5]. The virus also has been isolated from adult cattle experiencing acute diarrhea during outbreaks of winter dysentery (WD) [19]. In a recent study individ-

*Present address: Department of Veterinary and Biomedical Sciences, University of Nebraska, Lincoln, NE 68583, U.S.A. 
uals in herds experiencing WD were more likely to have recently seroresponded to BCV than individuals in non-affected herds [22]. However, the role of BCV in the WD syndrome remains unclear. A few attempts were made to experimentally reproduce WD in cows using feces from cows with WD as challenge inocula, but results have been inconsistent $[3,28]$. Certain risk factors combined with $\mathrm{BCV}$ infection might be important to initiate WD [22].

Antigenic, biological and genomic variations among BCV strains have been reported $[9,13]$. Recently, we also detected some antigenic and biological diversity among BCV strains, but these variations were unrelated to the clinical source of the strains; i.e. CD or WD [26]. Also we reported complete cross-protection and no differences in the pathogenicity between selected WD and CD BCV strains in experimentally infected gnotobiotic and colostrum-deprived calves [10]. However, the infectivity and pathogenicity of $\mathrm{CD}$ and WD BCV for adult cows is unclear. Electron microscopy (EM) is often used for the identification of BCV in feces $[2,6]$. However, sometimes it is difficult to identify BCV in feces by EM because pleomorphic membranous particles resembling coronaviruses are common in feces [19]. Nucleic acid based assays, especially PCR, have been used to detect enteric viruses [4, 14, 31].

The objectives of this study were: 1) to develop RT-PCR for the detection of $\mathrm{BCV}$ in feces; and 2) to attempt to experimentally reproduce WD in adult cows with $\mathrm{CD}$ and $\mathrm{WD}$ strains of $\mathrm{BCV}$ and to detect $\mathrm{BCV}$ in feces of these cows by RT-PCR.

The live virulent WD DBA and CD DB2 and 216XF strains of BCV were used in this study $[1,26]$. These strains were passaged in gnotobiotic calves (DBA and DB2) at leat 5 times or in colostrum-deprived calves (216XF) 2 times, and the large intestinal contents of the infected calves were harvested as inocula for this study. Electron microscopic examination of the inocula revealed the presence of BCV and no adventitious viruses. The following viruses were used for RT-PCR: Six strains (Mebus, DB2, 216XF, OHC, SDC and JAZ) of CD BCV [1, 26]; 8 strains (DBA, SD, CN, BE, AW, TS, BM and BW) of WD BCV [1, 26]; 2 deer coronavirus strains (KI-D2 and WTD) propagated in HRT-18 cells [25]; 3 group A rotavirus strains (NCDV Lincoln, Gottfried and OSU) propagated in MA104 cells; and a transmissible gastroenteritis virus strain (Purdue, P115) propagated in ST cells.

A total of 11 nonpregnant, nonlactating, adult, Hostein dairy cows ( 3 to 5 years of age) were used. Ten of these were inoculated with BCV and the remaining one was a non-inoculated control. These cows were housed separately in an infectious disease isolation facility, where temperature was controlled at about $20^{\circ} \mathrm{C}$, and hay and concentrate were fed during the experiments. These cows possessed antibodies to BCV by previous natural infection before challenge, and BCV was not detected from daily feces by ELISA and immune electron microscopy (IEM) at leat 1 week prior to the start of the experiments. A $20 \%$ suspension of the intestinal contents containing the DBA, DB2 or $216 \mathrm{XF}$ strain of BCV was administered using $10 \mathrm{ml}$ intranasally and $90 \mathrm{ml}$ through a surgically-placed duodenal catheter (Supraflex Trocar Catheter; Rusch Inc) (8 cows) or alternatively, given orally 
(2 cows) (Table 1). The surgery on the duodenal catheter was done at least 1 week before the experiments. Six cows received serial injections of dexamethasone (Schering-Plough Animal Health Corporation) (DM; $50 \mathrm{mg} /$ day) intramuscularly for 5 days prior to or after BCV challenge (Table 1). Forty liters of ice water were given to 2 cows through an intranasal catheter 2 times in the previous day and on the day of challenge. After inoculation of cows with BCV, feces and nasal swab specimens were collected daily, blood samples were collected at challenge and 14 to 21 days later, and clinical signs were observed through post-inoculation days (PID) 14 to 21 except for one cow (cow 5) euthanized at PID 4. One noninoculated control cow (cow 11) received serial injections of DM (50 mg/day) for 5 days and 40 liters of ice water for 2 days at the last day of DM treatment and for the next day. Feces and nasal swab specimens were collected from this cow for 19 days from the first day of DM treatment, blood samples were collected at the last day of DM treatment and 14 days later, and clinical signs were observed for 19 days from the first day of DM treatment. Feces were diluted 1:10 in $10 \mathrm{mM}$ phosphate-buffered saline (PBS; pH 7.4) for ELISA and IEM and 1:2 for RTPCR. Nasal epithelial cells were collected from nasal swab specimens and were used for direct immunofluorescence (IF) tests. One colostrum-deprived calf (28day-old) and a gnotobiotic calf (7-day-old) were inoculated oronasally with the DB2 and DBA strains of BCV, respectively. Feces were collected for 14 days and examined for BCV by ELISA, IEM and RT-PCR.

Fecal suspensions were processed and examined by IEM as described previously [20]. An ELISA using monoclonal antibodies to BCV for the detection of BCV antigen was conducted on the fecal samples as described previously [24]. Direct IF tests were performed with nasal epithelial cells using fluorescein isothiocyanate (FITC)-conjugated anti-BCV (Mebus strain) serum [21]. Virus neutralization $(\mathrm{VN})$ tests were conducted using HRT-18 cells as described previously [27]. Seroconversion was defined as a 4-fold or greater increase in serum antibody titers to BCV at 14 to 21 days after inoculation compared with those at inoculation.

An RT-PCR assay for detection of BCV was performed as follows. Viral RNA was extracted from $0.2 \mathrm{ml}$ of each fecal suspension and purified BCV (Mebus strain) using a Micro RNA isolation kit (Stratagene Cloning Systems), based on the acid guanidinium-phenol-chloroform RNA extraction method. The tissue culture-adapted viruses were used directly without RNA extraction. The primers for BCV were designed from the published sequence of the nucleocapsid gene of the Mebus strain [12]. The sequences of primers (positions calculated from the start codon of the nucleocapsid gene) were as follows: upstream primer 5'-GCCGATCAGTCCGACCAATC-3 (position, 92-111); downstream primer, 5'-AGAATGTCAGCCGGGGTAT-3' (position, 498-480). The predicted PCR product was 407 base pairs. The reverse transcriptase reaction was conducted by the following procedure. In the tube, $5 \mu \mathrm{l}$ of RNA sample was added to $2 \mu \mathrm{l}$ of the downstream primer ( $50 \mathrm{pmol})$ and $4 \mu \mathrm{l}$ of water. The tube was incubated at $100{ }^{\circ} \mathrm{C}$ for $2 \mathrm{~min}$ and then quenched on ice for $5 \mathrm{~min}$. Subsequently, $4 \mu \mathrm{l}$ of $5 \times$ RT buffer [250 mM tris- $\mathrm{HCl}(\mathrm{pH} 8.3), 375 \mathrm{mM} \mathrm{KCl}, 15 \mathrm{mM} \mathrm{MgCl}_{2}$ ], $2 \mu \mathrm{l}$ of 
H. Tsunemitsu et al.

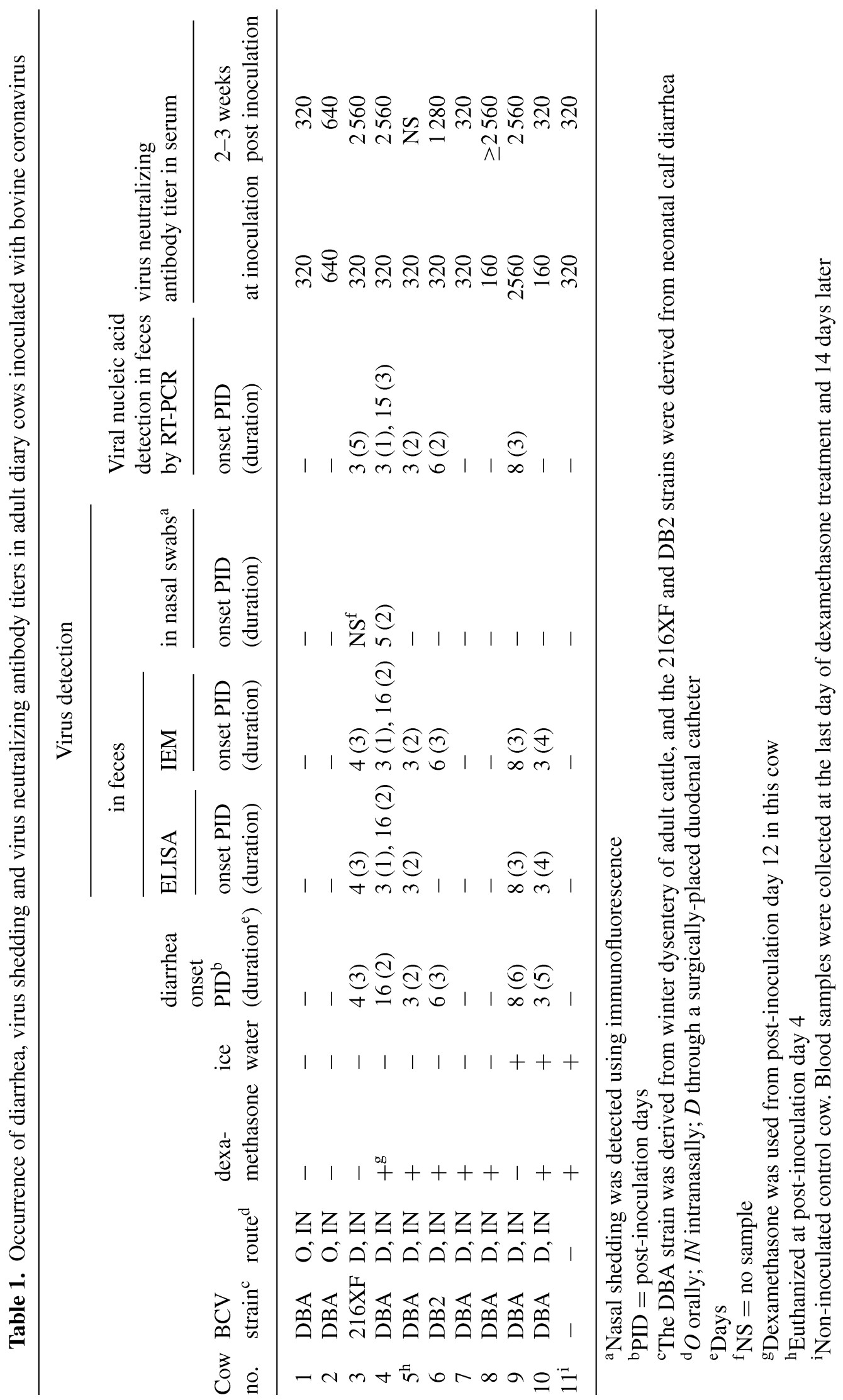


0.1 M dithiothereitol, $2 \mu l$ of $10 \mathrm{mM}$ dNTPs, $0.5 \mu l$ of RNAsin (Promega Corporation), and $0.5 \mu \mathrm{l}$ of Moloney murine leukemia virus RT (Gibco BRL Products) $(200 \mathrm{U} / \mu \mathrm{l})$ were added and incubated at $37^{\circ} \mathrm{C}$ for $60 \mathrm{~min}$. Then $5 \mu \mathrm{l}$ of the RT reaction samples were added to $95 \mu$ l of the PCR mixture. The PCR mixture consisted of $10 \mu \mathrm{l}$ of $10 \times$ PCR buffer [100 mM Tris-HCl $(\mathrm{pH} 8.3), 500 \mathrm{mM} \mathrm{KCl}$, $15 \mathrm{mM} \mathrm{MgCl}_{2}, 0.01 \%$ gelatin], $2 \mu \mathrm{l}$ of $10 \mathrm{mM}$ dNTPs, $1 \mu \mathrm{l}$ of the upstream primer (50 pmol), $1 \mu \mathrm{l}$ of the downstream primer (50 pmol), $80.5 \mu \mathrm{l}$ of water and $0.5 \mu \mathrm{l}$ of Taq polymerase (Promega Corporation) $(5 \mathrm{U} / \mu \mathrm{l})$. The mixture was overlaid with mineral oil and then subjected to 4 min of preheating at $94{ }^{\circ} \mathrm{C}, 30$ cycles of $1 \mathrm{~min}$ at $94{ }^{\circ} \mathrm{C}, 1 \mathrm{~min}$ at $58^{\circ} \mathrm{C}, 2 \mathrm{~min}$ at $72^{\circ} \mathrm{C}$, and a final $7 \mathrm{~min}$ incubation at $72{ }^{\circ} \mathrm{C}$. The PCR products were visualized on $1.2 \%$ agarose gels stained with ethidium bromide. Ten virus-negative feces collected from preexposure gnotobiotic or colostrum-deprived calves were used as negative controls.

PCR products of $407 \mathrm{bp}$ were found after RT-PCR with all $14 \mathrm{BCV}$ and 2 deer coronavirus strains. By contrast, rotaviruses, transmissible gastroenteritis virus and all 10 virus negative fecal samples were negative in the assay. As little as $1 \mathrm{pg}$ of purified BCV (Mebus strain) RNA and 0.1 TCID $_{50}$ of BCV (Mebus strain)-infected HRT-18 cell culture fluids could be detected in this assay. Fecal shedding of BCV by 2 calves was detected after inoculation by the RT-PCR for 8 days, whereas BCV was detected by IEM and ELISA for 4-5 days and 5-7 days, respectively.

Cows 1 and 2 inoculated oronasally with the WD BCV did not show clinical signs of BCV infection (Table 1). Therefore, other cows were inoculated through a duodenal catheter with and without DM or ice water. Cow 3, inoculated with a CD BCV, developed diarrhea from PID 4. The virus was detected in feces by IEM and ELISA from PID 4 for 3 days, and the RT-PCR showed positive reactions from PID 3 for 5 days (Fig. 1). Seroconversion was observed at 2 weeks after inoculation (Table 1). Cow 4 inoculated with WD BCV did not develop diarrhea through PID 12, but the virus was detected in the feces at PID 3 and in nasal epithelial cells at PID 5 and 6. At PID 12, this cow received serial injections of DM for 5 days. From the 5th day of DM treatment, she exhibited diarrhea for 2 days. The virus was detected by ELISA and IEM from the 5th day of DM treatment for 2 days, and RT-PCR showed positive reactions from the 4 th

$\begin{array}{lllllllllllll}0 & 1 & 2 & 3 & 4 & 5 & 6 & 7 & 8 & 9 & 10 & M\end{array}$

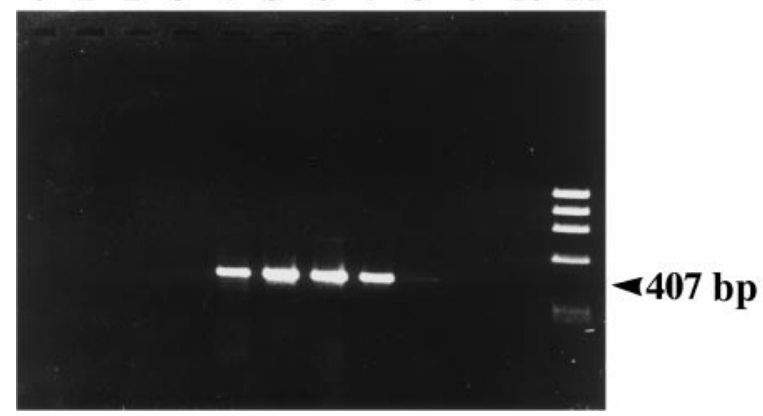

Fig. 1. RT-PCR detection of bovine coronavirus RNA in fecal samples of the experimentally inoculated adult dairy cow 3. The RT-PCR products were visualized on $1.2 \%$ agarose gels stained with ethidium bromide. Top numbers indicate days postinoculation. $M$ Molecular marker 
day of DM treatment for 3 days. Seroconversion was observed at 3 weeks after inoculation (Table 1). Cows 5, 6, 7 and 8 were treated with DM daily for 5 days prior to inoculation with the WD BCV (cows 5, 7,8) or CD BCV (cow 6). Cows 5 and 6 developed diarrhea from 3 and 6 PID, respectively. The feces of cows 5 and 6 were positive for BCV by all detection methods, and by IEM and RT-PCR from the day diarrhea commenced. In contrast, cows 7 and 8 did not develop diarrhea, and $\mathrm{BCV}$ shedding was not detected in feces, although seroconversion to BCV was observed in cow 8 (Table 1). Cows 9 and 10 were given ice water daily for 2 days and cow 10 was also treated with DM for 5 days prior to challenge with the WD BCV. Cows 9 and 10 developed diarrhea on PID 8 for 6 days or on PID 3 for 5 days, respectively. The feces of cow 9 were positive for BCV from the day diarrhea began for 3 days by all detection methods. The feces of cow 10 were positive for BCV from the onset of diarrhea through 4 days by ELISA and IEM, but negative by RT-PCR. Seroconversion to BCV was not observed in these 2 cows (Table 1). Cow 11, non-inoculated, but treated with dexamethasone and given ice water, showed neither clinical signs of BCV infection, BCV shedding, nor seroconversion (Table 1). All diarrheal feces of the cows were black, semiliquid, and no cow showed bloody diarrhea, fever, or respiratory symptoms.

Recently, an RT-PCR method was reported for the detection of human coronaviruses from nasal aspirates [15], but to our knowledge there are no reports of the diagnosis of BCV in feces by RT-PCR. We designed primers from the nucleocapsid gene because this gene is conserved among BCV strains [8]. All 14 stains of BCV including the DBA, DB2 and 216XF which were used for cow inoculations, and the deer coronaviruses were detected by RT-PCR, suggesting that the sequences of the primers used in this study were conserved among these BCV strains. The RT-PCR was more sensitive than ELISA and IEM to detect $\mathrm{BCV}$ in the feces of experimentally inoculated calves. For the majority of feces from the cows, samples positive by ELISA or IEM were also positive by RT-PCR. These results indicated that the RT-PCR developed might be useful for diagnosis of BCV infections in calves and adult cows. However, the feces of cow 10 at PID 3 to 6 were positive for BCV by ELISA and IEM, but not by RT-PCR. These negative results might be caused by the presence of inhibitory substances for PCR present in the feces of this animal [30].

Several risk factors for WD have been reported [3, 19, 22, 23, 29]. Especially, stress factors, such as dietary changes, parturition, lactation, chilling due to low environmental temperature or cold drinking water, or wide fluctuations in temperatures might play an important role in initiating the disease. Also, the immune status of cows [23] and mixed infections of BCV with other microorganisms might be contributory factors to the disease. At first, we tried to inoculate the virus oronasally to 2 cows, as was done previously for gnotobiotic or colostrumdeprived calves [10], but these cows did not show any clinical signs, virus shedding or increased serum antibody responses to BCV. These results indicate that unlike in calves [10], it is difficult to reproduce diarrhea in seropositive adult cows challenged with BCV via the oronasal route. In contrast, 6 of 8 cows inoculated through a duodenal catheter developed diarrhea and shed BCV in diarrheal feces. 
Viral inoculation via the duodenum excluded the adverse effects of rumen microorganisms and gastric acids in the abomasum on BCV. Certain stress factors, such as mentioned previously, may change the number and composition of rumen microorganisms, or increase the $\mathrm{pH}$ of the abomasum and influence BCV infectivity in the field. Immune suppression induced by DM treatment influenced the occurrence of diarrhea and virus shedding in our BCV challenge exposure studies, although exceptions occurred. For example, cow 4 began to show diarrhea and virus shedding during DM treatment. The DM treatment causes deleterious effects on mucosal immune responses as reported previously [16, 18] and likely also compromises mucosal immune responses and host resistance to $\mathrm{BCV}$. We gave a large volume of ice water to 2 cows as a stress inducer before inoculation and one of them was also treated with DM before inoculation. Both cows showed diarrhea and virus shedding, but there were no major differences between the 2 cows in the degree of diarrhea and the duration of virus shedding. However it was interesting that ice water treatment alone in cow 9 also resulted in BCV infection and diarrhea.

Chronic shedding of BCV in the feces of clinically normal cows has been reported [7], but no $\mathrm{BCV}$ was detected in feces from these cows for at least 1 week prior to the start of these experiments. Also, one non-inoculated control cow, which was treated with dexamethasone and given ice water, did not show $\mathrm{BCV}$ shedding or diarrhea. Therefore, there is a low possibility that the BCV detected in the feces of cows after inoculation was endogenous BCV.

Pre-existing serum VN antibody titers to BCV did not protect cows against $\mathrm{BCV}$ infections in this study. No obvious agreement was evident between the antibody titer and the degree of protection. For example, the antibody titer of cow 7 was low at challenge (320), and this cow did not show any clinical signs of BCV infection. In contrast, cow 9 had a hight serum antibody titer (2560) at challenge, but developed diarrhea and shed virus. Most adult dairy cattle are seropositive to BCV $[19,22]$. Further analysis of intestinal antibody titers to BCV in cows is needed to help clarify whether they are an indicator of protection [11]. Diarrhea in this cow-challenge exposure model was mild, and no bloody feces were observed. Further studies are needed to determine other significant risk factors to reproduce WD, in particular the bloody diarrhea sometimes observed in a percentage of the affected cows [19].

Bovine coronavirus causes neonatal CD and is also detected from adult cattle with WD. Based on epidemiological data, these disease syndromes often occur as separate and distinct outbreaks in herds; therefore differences in pathogenicity and antigenicity between CD and WD BCV might be expected $[9,13,19]$. However, isolates of WD BCV were reported to produce bloody diarrhea [17] or watery diarrhea [10] in newborn calves. Our previous results indicated that the degree of diarrhea and the patterns of fecal and nasal shedding of BCV were indistinguishable between the CD DB2 and WD DBA strains based on crossprotection studies in calves [10], suggesting that WD BCV strains cause diarrhea in calves. Also, there were no relationships between the antigenic and biological diversity among BCV strains and the clinical sources (WD and CD) of the strains 
[26]. In this study, 2 of 2 cows inoculated with the DB2 or $216 X F$ strain of CD $\mathrm{BCV}$, and 4 of 6 cows inoculated with the DBA strain of WD BCV via a doudenal catheter developed diarrhea and shed virus. These results suggest that $\mathrm{CD}$ and WD BCV can cause diarrhea in adult cows in combination with host or environmental factors, and these factors might contribute to the separate and distinct nature of the WD and CD outbreaks.

\section{References}

1. Benfield DA, Saif LJ (1990) Cell culture propagation of a coronavirus isolated from cows with winter dysentery. J Clin Microbiol 28: 1454-1 457

2. Bulgin MS, Ward AS, Barrett DP, Lane VM (1989) Detection of rotavirus and coronavirus shedding in two beef cow herds in Idaho. Can Vet J 30: 235-239

3. Campbell SG, Cookingham CA (1978) The enigma of winter dysentery. Cornell Vet 68 : 423-441

4. Chinsangaram J, Akita GY, Osburn B (1994) Detection of bovine group B rotaviruses in feces by pollymerase chain reaction. J Vet Diagn Invest 6: 302-307

5. Clark MA (1993) Bovine coronavirus. Br Vet J 149: 51-70

6. Collins JK, Riegel CA, Olson JD, Fountain A (1987) Shedding of enteric coronavirus in adult cattle. Am J Vet Res 48: 361-365

7. Crouch CF, Ohmann HB, Watts TC, Babiuk LA (1985) Chronic shedding of bovine enteric coronavirus antigen-antibody complexes by clinically normal cows. J Gen Virol 66: $1489-1500$

8. Cruciere, C, Laporte J (1988) Sequence and analysis of bovine enteric coronavirus (F15) genome. 1. Sequence of the gene coding for the nucleocapsid protein; analysis of the predicted protein. Am Inst Pasteur Virol 139: 123-138

9. Dea S, Michaud L, Rekik R (1995) Antigenic and genomic variations among cytopathic and non-cytopathic strains of bovine enteric coronavirus. Adv Exp Med Biol 380: 99-101

10. El-Kanawati ZR, Tsunemitsu H, Smith DR, Saif LJ (1996) Infection and cross-protection studies of winter dysentery and calf diarrhea bovine coronavirus strains in colostrumdeprived and gnotobiotic calves. Am J Vet Res 57: 48-53

11. Feng N, Burns JW, Bracy L, Greenberg HB (1994) Comparison of mucosal and systemic humoral immune responses and subsequent protection in mice orally inoculated with a homologous or a heterologous rotavirus. J Virol 68: 7 766-7 733

12. Lapps W, Hogue BG, Brian DA (1987) Sequence analysis of the bovine coronavirus nucleocapsid and matrix protein genes. Virology 157: 47-57

13. Millane G, Michaud L, Dea S (1995) Biological and molecular differentiation between coronaviruses associated with neonatal calf diarrhoea and winter dysentery in adult cattle. Adv Exp Med Biol 380: 29-33

14. Moe CL, Gentsch J, Ando T, Grohmann G, Monroe SS, Jiang X, Wang J, Estes MK, Seto Y, Humphrey C, Stine S, Glass RI (1994) Application of PCR to detect Norwalk virus in fecal specimens from outbreaks of gastroenteritis. J Clin Microbiol 32: 642-648

15. Myint S, Johnston S, Sanderson G (1994) Evaluation of nested polymerase chain methods for the detection of human coronaviruses 229E and OC43. Mol Cell Probes 8: 357-364

16. Oldham G, Bridger JC (1992) The effect of dexamethasone-induced immunosuppression on the development of faecal antibody and recovery from and resistance to rotavirus infection. Vet Immunol Immunopathol 32: 77-92 
17. Rogan D, Dea S, Percy D, Culbert R (1996) Ability of winter dysentery isolates of bovine coronaviruses to induce bloody diarrhea in newborn calves. Conference of Research Workers in Animal Diseases, Chicago IL, Abstract 107

18. Roy MJ, Walsh TJ (1992) Histopathologic and immunohistochemical change in gutassociated lymphoid tissues after treatment of rabbits with dexamethasone. Lab Invest 64: 437-443

19. Saif (1990) A review of evidence implicating bovine coronavirus in the etiology of winter dysentery cows: an enigma resolved? Cornell Vet 80: 303-311

20. Saif L J, Bohl EH, Kohler EM, Hughes JH (1977) Immune electron microscopy of transmissible gastroenteritis virus and rotavirus (reovirus-like agent) of swine. Am J Vet Res 1977 38: 13-20

21. Saif LJ, Redman DR, Moorhead PD, Theil KW (1986) Experimentally induced coronavirus infections in calves: viral replication in the respiratory and intestinal tracts. Am J Vet Res 47: 1426-1 432

22. Smith DR, Fedorka-Cray PJ, Mohan R, Brock KV, Wittum TE, Morley PS, Hoblet KH, Saif LJ (1998) Epidemiologic herd-level assessment of causative agents and risk factors for winter dysentery in dairy cattle. Am J Vet Res 59: 994-1001

23. Smith DR, Fedorka-Cray PJ, Mohan R, Brock KV, Wittum TE, Morley PS, Hoblet KH, Saif LJ (1998) Evaluation of Cow-level risk factors for the development of winter dysentery in dairy cattle. Am J Vet Res 59: 986-993

24. Smith DR, Tsunemitsu H, Heckert RA, Saif LJ (1996) Evaluation of two antigen-capture ELISAs using polyclonal or monoclonal antibodies for the detection of bovine coronavirus. J Vet Diagn Invest 8: 99-105

25. Tsunemitsu H, El-Kanawati ZR, Smith DR, Reed Saif LJ (1995) Isolation of coronaviruses antigenically indistinguishable from bovine coronavirus from wild ruminants with diarrhea. J Clin Microbiol 33: 3 264-3 269

26. Tsunemitsu H, Saif LJ (1995) Antigenic and biological comparisons of bovine coronaviruses derived from neonatal calf diarrhea and winter dysentery of adult cattle. Arch Virol 140: 1303-1311

27. Tsunemitsu H, Yonemichi H, Hirai T, Kudo T, Onoe S, Mori K, Shimizu M (1991) Isolation of bovine coronavirus from feces and nasal swabs of calves with diarrhea. J Vet Med Sci 53: 433-437

28. VanKruiningen RJ, Hill SL, Tilton RC, Ryan RW (1995) Winter dysentery in dairy cattle: recent findings. Comp Cont Ed 7: S591-S599

29. White ME, Schukken YH, Tanksley B (1989) Space-time clustering of, and risk factors for, farmer-diagnosed winter dysentery in dairy cattle. Can Vet J 30: 948-951

30. Wilde J, Eiden J, Yolken R (1990) Removal of inhibitory substances from human fecal specimens for detection of group A rotaviruses by reverse transcriptase and polymerase chain reactions. J Clin Microbiol 28: 1300-1 307

31. Xu L, Harbour D, McCrae MA (1990) The application of polymerase chain reaction to the detection of rotavirus in faeces. J Virol Methods 27: 29-38

Authors' address: Dr. L. J. Saif, Food Animal Health Research Program, Ohio Agricultural Research and Development Center, 1680 Madison Avenue, Wooster, OH 44691, U.S.A

Received June 22, 1998 